\title{
A CAPOEIRA EM DIMENSÕES URBANAS E SOCIOANTROPOLÓGICAS: 0 BATIZADO EM BENJAMIN CONSTANT- AM
}

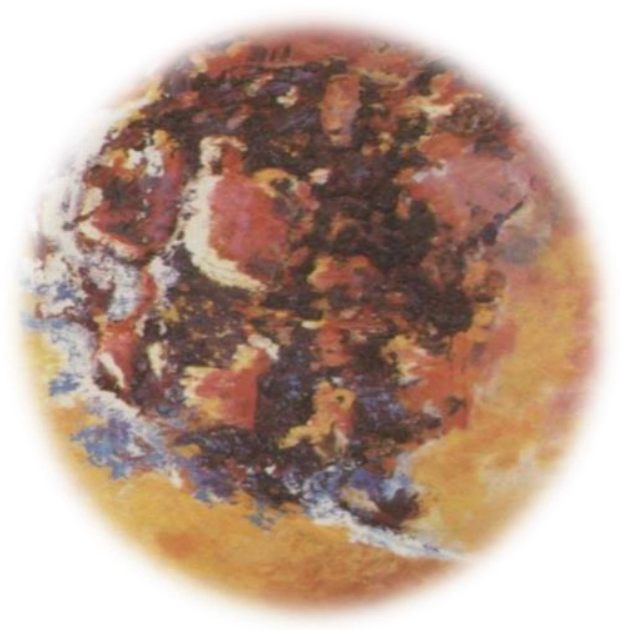

Tharcisio Santiago Crur

\section{Resumo}

Neste artigo desenvolvo uma abordagem socioantropológica sobre a capoeira, especificamente uma descrição-etnográfica do "Batizado", ou seja, adentro num ritual de passagem, normalmente realizado uma vez por ano. Como campo de análise escolhi a realização deste evento em Benjamin Constant, município localizado no Alto Solimões-Amazonas.

Palavras-chave: Capoeira. Socioantropologia. Batizado.

\section{A capoeira em interpretações diversas}

O Antropólogo Gilberto Freyre em Sobrados e Mucambos faz menção a capoeira como prática oriunda do meio rural a partir da luta e defesa dos trabalhadores escravos nas fazendas do nordeste brasileiro. No livro, Freyre

1 - Professor Assistente de Sociologia no INC/UFAM, doutorando pelo Programa de Pós-Graduação em Antropologia Social/PPGAS/UFAM. 
ressalta o caráter das técnicas da capoeira, principalmente quando menciona episódios e lugares em que estas técnicas eram utilizadas em:

[...] procissões com banda de música tornaram-se o ponto de encontro dos capoeiras, curioso tipo de negro ou mulato de cidade, correspondendo ao dos capangas e cabras dos engenhos. A capoeiragem incluía, além disso, uma série de passos difíceis e de agilidades quase incríveis de corpo...(FREYRE, 2004, p. 189).

Em Benjamin Constant ${ }^{2}$, a capoeira é interpretada dentro de uma imagem de mistério, algo diferente em relação ao modo de vida e de lugar em que a comunidade local lida em sua existência urbana.

Escrever sobre este tema tornou-se para mim um instigante desafio, por ter participado e acompanhado os batizados do grupo de capoeira Negros no Amazonas, de 2010 a 2016. Trata-se aqui de um relato de alguém que "esteve lá" corroborando com a contribuição metodológica de Roberto Cardoso de Oliveira (2006), que em certa medida pontua o vivenciar como uma " primeira etapa", para o antropólogo "[... ]devemos entender, assim, por escrever o ato por excelência no gabinete, cujas características o singularizam de forma marcante, sobretudo quando o comparamos com o que se escreve no campo[...]". Neste caso além do uso diário sobressai a convivência de mais de sete anos com o grupo do qual pertenço, na condição de capoeirista.

Em certa medida exponho aqui a assertiva teórica de Geertz (2005), a de "Estar lá" e o desafio da escrita de quem viveu ou a mesma pessoa que um dia teve que "desembarcar", ou mesmo, "suportar a solidão" até fazer parte de uma comunidade e de vivenciar o universo cultural da capoeira, neste caso em Benjamin Constant.

2- Benjamin Constant, município localizado na mesorregião do Alto-Solimões, distante $1250 \mathrm{Km}$ de Manaus a capital do Amazonas. De acordo com o censo do IBGE de 2010, possui uma população de 35.000 habitantes. No município atuam dois grupos de capoeira: Quilombo e Negros do Amazonas. No município está situado o Instituto de Natureza e Cultura no campus da Universidade Federal do Amazonas. 
Este desafio se faz menos árduo, se nos dispomos a perspectiva metodológica de Rodrigues (2008), no tocante as inúmeras possibilidades de interpretação das sociabilidades que se constituem em determinados espaços urbanos, devemos assim segundo a autora, "considerar as interpretações dos próprios moradores fazem de suas vivências e experiências individuais ou coletivas no contexto urbano, ou significados por eles atribuídos a essas vivências[...]" (p.15).

Neste artigo procuro destacar dentro da prática cultural da capoeira, a realização do batizado a partir da observação e vivência sistemática, numa interpretação da condição de protagonização de "atividades coletivas" (Rodrigues, 2008), escolhendo como lugar a praça Frei Ludovico na parte central de Benjamin Constant, espaço público de preparo para este ritual que ocorre anualmente no município.

Considero assim com a noção de práticas culturais compartilhadas por Rodrigues (2008), no sentido de participação dos agentes que produzem e vivenciam tais práticas nos eventos de capoeira ao longo do ano, que preparam em certa medida o batizado possibilitando uma demarcação de espaços de sociabilidade no município.

\section{Quem é o capoeirista em Benjamin Constant?}

Em Benjamin Constant, o capoeirista não é diferente como em qualquer parte do Brasil e do mundo, normalmente trata-se de pessoas que tem uma relação de convivência de décadas com a capoeira, diferentemente do praticante de capoeira que pode ser: que frequenta eventualmente por: dias, meses ou anos e se desliga desta prática cultural e para assumir outra qualquer atividade social, como: trabalhar, se dedicar aos estudos; praticar um outro esporte ou luta e cuidar da família. Já o capoeirista consegue assumir algumas destas atividades, principalmente: trabalhar, cuidar da familiar e continuar ao longo da vida, mantendo uma relação com a capoeira. 
É muito comum que seus filhos comecem a praticar capoeira desde muito pequenos, e assim inseridos neste universo.

O capoeirista vivencia de certa forma parte da realidade do que FootWhitee (1970) a existência de um grupo junto aos que se formam ao seu redor. $\mathrm{O}$ autor se refere é claro a um personagem, ou seja, aquele com características de líder, que tem estas qualidades sendo desenvolvidas e experimentadas desde criança. Com o mestre Gigante não foi diferente, desde que iniciou a praticar capoeira nos anos de 1990, aos12 anos já ensinava essa arte, a mesma idade de $D o c^{3}$ o principal personagem de etnografia de Whyte:

Tinha por volta de 12 anos quando me envolvi em minha primeira briga... A princípio, eu não queria, mas finalmente briguei com o garoto e dei uma surra nele.... Depois, comecei a pensar que talvez até fosse bastante bom nisso[...] (WHYTE, p.28).

Em Benjamin Constant, não é diferente, apesar de se tratar de um município localizado em uma outra parte das Américas, diacronicamente os atores sociais também se submetem a ritos, capoeira apenas apresenta diferentes rituais de passagem, o Batizado que apresento aqui é o principal deles.

Nos relata o Mestre Gigante, que na década de 2000, atuava ministrando aulas de capoeira em Leticia - Colômbia e nesta ocasião foi convidado a realizar esta atividade em Bogotá. Relata o mestre, “[...]pensei muito nesta aventura, mas pensei também na família, resolvi não ir[...]”. Este é um exemplo de um mestre de capoeira, que poderia ter continuado uma

3 - Trata-se aqui de personagem que atuou em um ambiente do que era a Corneville, em Boston dos anos de 1930, mas que revela em parte o universo de formação de crianças, adolescentes e jovens em que os desafios e rituais se fazem presentes. 
carreira internacional $^{4}$, mas preferiu constituir uma vida familiar e na capoeira em seu país, apesar de se tratar de uma oportunidade que apresentava possibilidade de ganhos financeiros bem melhores que no Brasil.

Em termos gerais, os capoeiristas fora do Brasil são conhecidos como: mestres, que já alcançaram o reconhecimento desta condição no mundo da capoeira, contramestres que estão neste processo e professores que se encontram em processo de avaliação principalmente pelos mestres. Só o mestre detém a prerrogativa de conceder as devidas graduações e reconhecimentos aos contramestres e mestres.

No tocante aos praticantes de capoeira, em outros países, estes em sua maioria, são estudantes e pessoas que já tem uma atividade profissional qualificada, nutrem primeiramente curiosidade pela capoeira em diversos aspectos como: o caráter desportivo e de luta, histórico-cultural.

Percebemos tal constatação a partir dos relatos e convivência com os praticantes em Leticia e alguns de Bogotá, normalmente são: professores, advogados, servidores públicos, etc. Situação bem diferente dos capoeiristas e praticantes de capoeira em Benjamin Constant, que em sua maioria não possuem uma atividade profissional qualificada, em termos de mercado de trabalho, normalmente, são: carregadores, moto- taxistas, trabalhadores do comércio e estudantes do ensino fundamental, médio e Educação de Jovens e Adultos.

No caso do grupo de Capoeira Negros do Amazonas, elenco a seguinte composição profissional dos capoeiristas: Mestre Gigante - Técnico em Eletricidade e Bacharel em Antropologia, Professor Toquinho - Barbeiro,

4 -Este é um dos principais fatores que motivaram os capoeiristas brasileiros na década e 1970 a investir em carreira fora do Brasil, estes são conhecidos como os primeiros a investir em tal atividade, são estes. Trata-se ainda hoje de um dos principais motivos para estes agentes tal atividade, são estes: Trata-se ainda hoje de um dos principais motivos para estes agentes continuarem e tentar uma vida como professores de capoeira em vários países, principalmente na Europa e EUA). 
Instrutor Maminha ${ }^{5}$ - Professor Universitário e doutorando, Instrutor RobôMotorista profissional, Monitor Jogo de Dentro- estudante; Monitor Oscar - estudante. Não é comum em um município do interior do Amazonas uma diversidade profissional desta ordem, tal fator atribui-se principalmente a existência da UFAM no município, instituição que exerce influência na educação no Alto Solimões.

Os praticantes são em sua maioria crianças, adolescentes estudantes em diversos níveis. Sobre o número de praticantes há uma oscilação que gira e torno de 10 a 80 praticantes, entre os anos de 2010 a 2017. Em 2015 eram 35, 2016-20, 2017 -15, o número de praticantes tem diminuído. Conversando com os praticantes, percebeu-se que o argumento principal dado por estes, relaciona-se a: necessidade de trabalhar e submissão ao serviço militar.

\section{A praça Frei Ludovico: o Lugar e as pessoas}

Imaginar uma relação entre os municípios do Amazonas e a presença "Negra", não tem sido tarefa confortável, principalmente devido a invisibilidade da população negra na região, a capoeira em Benjamin Constant pode ser analisada sob este aspecto. Esta prática cultural continua a ser interpretada como algo que veio de fora, mas "sem se saber quem a trouxe", é o que se ouve entre a comunidade local.

Percebe-se que se construiu uma imagem de algo estranho e que desperta curiosidade, principalmente devido ás apresentações na praça Frei

5 - Relato que na condição de professor universitário, tive a oportunidade de ministrar a disciplina Estudos Afro-brasileiros, pelo bacharelado em Antropologia e esta foi uma oportunidade de inserir a temática da capoeira no Plano de Curso, paralelamente à frente do Núcleo de Estudos Afro indígenas, criado em 2012, foi possível qualificar o debate sobre a capoeira e inseri-la em atividades acadêmicas e comunitárias, como exemplo o apoio aos Batizados do grupo. 
Ludovico, área central do município em frente a igreja matriz. Um outro local e momento de destaque é quando da realização dos Batizados, normalmente na Escola Estadual Professora Rosa Cruz, local onde ocorrem os treinos durante todo o ano.

Há, porém, outro aspecto com relação a capoeira no município este é mais preocupante, trata-se do víeis de preconceito, persiste o Estigma que é muito comum em outras regiões do país, que categoriza a capoeira como algo negativo, houve-se em Benjamin Constant, que, “...capoeira e coisa de vagabundo...”, “...é coisa que os pretos trouxeram para cá...” ou “...não quero meu filho envolvido com coisa de vagabundo...”.

Neste sentido prevalece o Estigma sobre a capoeira, é o que define Goffmam (2014), no sentido de que aqueles que participam do universo da capoeira, interpretam um papel e colocam em evidencia uma representação e "implicitamente é observado" ao mesmo tempo aciona na memória social a imagem que a capoeira construiu no passado de violência e luta, infelizmente as razões pelas quais a capoeira protagonizou tais práticas ainda é quase que desconhecida.

Farias et al (2006) possibilita uma melhor compreensão sobre este histórico de violência na capoeira no século XIX, devido a imagem que a sociedade tinha da capoeira e do capoeirista,

[...]que era um afigura de rua característica, mais do que uma pratica, muitas vezes mencionada como "jogo do capoeira". Em algum momento, houve uma fusão de significados. E a capoeira passa a ser um tipo de crime relacionado à experiência negra urbana (FARIAS ET AL. 2006, p.79).

Neste século, os capoeiristas se organizavam nas chamadas e temíveis maltas $^{6}$, denominadas de "Maltas de capoeiras", isto corresponde há um

6 - Sobre Maltas consultar, Soares, Libano C. R. A capoeira escrava no Rio de Janeiro: 1808-1850.Tese de doutoramento. Campinas, 1998. 
momento de significativa organização e disputas por espaços dentro da cidade do Rio de Janeiro no século XIX.

Estas falas, podem ser entendidas na perspectiva que versa sobre os limites da percepção dos moradores de um município, este, com fortes características rurais, que tem como atividades principais de sustentação de sua população: a pesca, agricultura familiar, serviço público e aposentadorias, percebe-se que apesar destes aspectos o município conta com uma estrutura de urbanidade, principalmente com construções de alvenaria como: hotéis , escolas, sedes dos órgãos de administração municipal, comercio em geral, ruas com asfaltamento, energia termoelétrica, sistema de abastecimento de água, iluminação das ruas, escolas e universidade pública.

$\mathrm{Na}$ composição de moradias do município, esta oscila entre uma infraestrutura composta por uma significativa quantidade de casas de madeira, distribuídas entre seus bairros. ${ }^{7}$

A praça central, Frei Ludovico, foi no passado de responsabilidade e uso da Paróquia de Nossa Senhora da Conceição, ligada a Prelazia do Alto Solimões o que remonta a uma intervenção no espaço público desde a década de 1940. A praça é um local em que poucos vendedores ambulantes tem atividade regular: quatro barracas de vendedores de lanches, um baleiro, um vendedor de cerveja e refrigerantes, ao fundo dois bares, normalmente muito frequentados.

No local são realizadas as apresentações de capoeira a partir das dezenove horas aos sábados pelo grupo de capoeira Quilombo, representado pelo contramestre Girafa e aos domingos o grupo Negros no Amazonas, sob a coordenação do Mestre Gigante.

7 - Centro, Colônia, Coimbra, Castanhal, Javarizinho, Cohabam, Umarizal, Bom Jardim com mais de 40 aos de existência e os mais recentes: Agropalme, Cidade Nova e Eduardo Braga. 
O público que assiste as apresentações é composto normalmente por pessoas da comunidade local, como: casais que levam suas crianças para passear, com grande número de peruanos ${ }^{8}$ que moram no município e tem um olhar destacadamente de admiração e curiosidade com relação a capoeira.

A Igreja local parece nunca ter aceitado bem a prática da capoeira na praça, mas não interfere. De qualquer modo é perceptível o incomodo, devido ao horário da celebração. Não raras vezes já percebi algumas senhoras fazendo o gesto de "sinal da Cruz" ao passar próximo a roda de capoeira, é o mesmo sinal de "proteção" que os capoeiristas fazem antes de iniciar o primeiro jogo de capoeira na roda, ou seja, sentidos diferentes num claro significado simbólico de ambos os lados. A igreja possui uma escadaria que lembra a da Igreja de Nossa Senhora do Bonfim na Bahia as cenas cinematográficas do filme O Pagador de promessas.

$\mathrm{Na}$ perspectiva de Antônio Arantes (2015) tal fenômeno, de se benzer, apresenta a oportunidade de manifestação neste cenário, "fenômenos liminares", ambivalentes, inseridos em posições atribuídas pelos integrantes de cada grupo, se sobressaem os significados simbólicos e de convenções.

Com relação á aqueles que participam da capoeira em Benjamim Constant, procuro aqui para melhor compreensão dos leitores, inseri-los em algumas categorias: a primeira os capoeiristas, ou seja aqueles que tem na capoeira um elemento cultural que já faz parte da própria vida, normalmente estes reservam momentos durante o dia para a capoeira: treino, trabalho com instrumentos musicais, ensinando a capoeira, como atividade remunerada ou voluntária, temporalmente tal relação varia entre anos e décadas.

8 - Peruanos em sua maioria que migraram do distrito de Iquitos no Peru, migram para os municípios do Alto Solimões, na perspectiva de " mudar de vida" para melhor, condição que já foi analisada por Roberto Cardoso de Oliveira (1969). 
Os praticantes de capoeira, que tem de início um forte envolvimento com esta arte, e dedicam aos treinos e alguns ao toque de instrumentos, mas essa relação sofre mudanças quando estes precisam: trabalhar, participar do serviço militar obrigatório ou mesmo assumir a própria família.

Os iniciantes têm uma importância fundamental na capoeira em Benjamin Constant, por se tratar em sua maioria de crianças e adolescentes que podem nesta pratica se encontrar e seguir um caminho na capoeira, como obter as primeiras noções de equilíbrio corporal, de acordo com os exercício e golpes de capoeira.

Em Benjamin Constant, os iniciantes têm a oportunidade de obter as primeiras noções sobre cultura afro-brasileira, já que foi possível inserir no cotidiano de treinos e conversas, elementos históricos sobre África, afrodescendentes e sobre as origens da capoeira.

Praticantes e iniciantes permitem que os capoeiristas desenvolvam seu aprendizado e métodos de ensino da capoeira, possibilitam que a Associação de Capoeira Negros no Amazonas, possa em certa medida existir enquanto grupo no sentido de coletividade em torno desta arte. Estes também contribuem para difundir noções sobre o significado da capoeira no município, como: arte, luta e elemento da cultura afro-brasileira.

De acordo com Cruz, T. e Cruz, F. (2016), o mestre Gigante inicia seu trabalho com capoeira em Benjamin Constant em 2002. Ressalta, porém, que já existia um trabalho com capoeira sob a coordenação de I. F. N (Contramestre Girafa), no mesmo ano:

a Associação Palmares de Capoeira é extinta, passa a ser denominada de Grupo Quilombo de Capoeira. No ano de 2003 o professor de capoeira Ivan Freitas do Nascimento inicia um programa de capoeira destinado ao público das escolas municipais, que não faziam parte dos Programas. É o Projeto Capoeira Quilombo (Capoeira na escola) que oportunizava os discentes das escolas das redes públicas de ensino municipal e estadual o acesso a capoeira (CRUZ, T. e CRUZ, F. 2016, p.133). 
O mestre Gigante nos relatou que foi responsável por um trabalho de capoeira junto a comunidade, dentro de um projeto denominado "Amigo da Escola”, e pôde assim,

Realizar seu $1^{\circ}$ trabalho com o Grupo de Capoeira Muzenza no município de Benjamin Constant... desenvolveu um programa de capoeira com crianças e adolescentes pertencentes a escola e comunidade local. No final de 2003 o grupo realiza o seu primeiro batizado (CRUZ, T. e CRUZ, F. 2016, p.133).

\section{O Batizado na capoeira}

Na linguagem da capoeira o "Batizado é um ritual, uma cerimônia, uma festa..." são palavras proferidas no que denominamos "mundo da Capoeira" esta noção é desde cedo transmitida principalmente aos praticantes pelos capoeiristas.

Trata-se de uma noção que é definidora neste universo, no sentido em que demarca e demonstra as posições e lugares em seu interior, traz ao mesmo tempo elementos tradicional, como uma pratica que é renovada a partir de sua repetição a cada ano, nos lembra o sociólogo Pierre Bourdieu (2008) e a noção de hábitus, como elemento estruturado e estruturante, pois renova-se a cada ano.

O Batizado em si, marca o momento em que capoeiristas e praticantes, se encontram em igual espaço no sentido de respeito e submissão ao rito. O lugar onde ocorrera o batizado, nesse caso a quadra esportiva da Escola Rosa Cruz, deve ser previamente preparado, com: a organização da mesa de convidados, a mesa onde ficam as cordas, os instrumentos musicais a serem utilizados (berimbaus, pandeiros e atabaques, agogôs e reco-recos). Podem tocar os instrumentos, capoeiristas, praticantes ou alguém que saiba tocar e seja convidado.

Os mestres iniciam a cerimonia pedindo que se organize a roda e que todos que participa da roda se organizem de acordo com suas graduações: 
mestres, ${ }^{9}$ contramentes e professores ficam mais próximos aos instrumentos, os praticantes e iniciados se distribuem na circularidade da roda.

O mestre gigante pronuncia "Salve a capoeira" e todos respondem, em seguida pede que se levantassem para ouvir o hino nacional, chama para próximo dos instrumentos os convidados de outros grupos, iniciando pelos mestres, contramestres, professores, instrutores e monitores, em seguida é dada a palavra aos mestres que se apresentam, seus grupos e fazem os agradecimentos pelo convite.

Em seguida o mestre inicia o ritual com o toque de berimbal $^{10}$ tocando o hino da capoeira, ou seja o toque Amazonas, para que todos façam referência ao significado deste toque, posteriormente o toque de Angola e São Bento Pequeno numa respeitosa menção ao mestre Pastinha e sua condição de tradição na capoeira, neste momento os mestres e contramestres iniciam o Jogo Angola, catando as músicas que o mestre Pastinha cantava na Bahia nos anos de 1920.O próximo toque e jogo é o de Benguela, seguido pelo jogo de Iuna e finalmente jogo de São Bento Grande, também conhecido como regional.

Estes são conhecidos como os jogos que iniciam o Batizado, participam apenas capoeiristas, com graduações mais elevadas que vão de monitores á mestre. O mestre retoma a palavra após a parte inicial para inicias o batizado, é o momento em que os iniciados na capoeira e praticantes iniciam sua participação na cerimônia. Cada um destes fara seu jogo de batizado,

9 - Existe um modelo de hierarquia na capoeira, que estabelece a condição de mestre ao capoeirista mais antigo que foi submetido a u processo de avaliação por outros mestres, passou pelo ritual e passou a ser reconhecido dentro desta categoria. O contramestre se encontra neste processo de avaliação. O professor da mesma forma,

10 - O berimbal é o instrumento de referência dentro e fora da capoeira. A partir deste instrumento os capoeiristas iniciam uma sequência de toque que acional os jogos na capoeira, são estes: Amazonas (Hino da capoeira), Angola (capoeira angola); Benguela (Referência a África). Iuna (Canto do pássaro); São Bento Grande (capoeira Regional). 
jogando com o capoeirista que o irá batizar. Após início do jogo o capoeirista tenta até conseguir aplicar um golpe que derrubara o iniciante e praticante, normalmente o golpe ${ }^{11}$ da rasteira muito usado no jogo da capoeira, o início recebe então sua primeira corda e seu nome ou apelido na capoeira.

Ao mesmo tempo aquele que resistem a esta parte do ritual são vistos pelos capoeiristas como guerreiros e preparados para as etapas posterior e neste universo. Há também o sentimento da parte daqueles que passam pelo o batizado de se sentirem preparados para continuar na capoeira.

Posteriormente é a vez dos praticantes, ou seja, aqueles que já foram batizados em anos anteriores e que agora irão avanças em sua graduação, jogando e recebem o além dos golpes ao final sua nova corda que é identificada na capoeira regional pela cor, variando também de grupo para grupo.

Após todos os praticantes terem passado pelo ritual de troca de cordas é a vez dos próprios capoeiristas. Trata-se de um momento muito aguardado pelo público que assiste ao batizado, pois é o momento em que o jogo regional se torna mais veloz e violento, pois jogam aqueles que já tem anos de prática, as vezes décadas. Os capoeiristas terão que jogar com vários outros, um por vez, sendo os últimos o contramestre e o mestre, este então fará o breve pronunciamento elencando as qualidades do capoeirista antes da entrega da corda.

Após quatro e cinco horas de início, o batizado é encerrado com a roda final, em que todos participam inclusive quem assiste a cerimonia, se assim desejar, os momentos finais o toque do berimbal torna-se mais veloz,

11 -A aplicação deste golpe varia de grupo para grupo, podendo ser uma simples rasteira em que o capoeirista te a preocupação de não machucar o iniciado ou mesmo o golpe considerado violento como: benção, martelo, arrastão, pizão cruzado, meia lua de compasso, rabo de arraia, etc. Esta pratica é uma das mais rejeitadas por aqueles que estão assistindo o batizado, o que leva muitas vezes os iniciados e praticantes a abandonarem a capoeira. Esclarecendo que se trata uma prática que compõem o universo de luta e ritual de passagem na capoeira, como em várias outras modalidades de práticas culturais e de luta. 
assim como os demais instrumentos, o jogo também se torna mais ligeiro, os golpes são aplicados com maior velocidade é possível perceber uma energia ${ }^{12}$ muito forte na roda de capoeira.

Cabe aqui ressaltar que toda esta descrição é referente ao batizado na capoeira de modalidade regional, que é também copiado na capoeira contemporânea, mas que se difere quase que por completo das cerimônias da capoeira Angola, denominada com a que representa a tradição nesta prática cultural. Trata-se de um outro universo da capoeira, com organização completamente diferente, a começar pela ordenação dos instrumentos e a não adoção de corda ${ }^{13}$ como instrumento de graduação ${ }^{14}$.

\section{A capoeira em ritos de passagem}

$\mathrm{Na}$ Capoeira encontramos um rito de passagem ou de iniciação, o batizado, este pertence ao universo histórico e mítico da capoeira, como descreve Cruz e Cruz, 2016,

a roda de capoeira é um ritual que começa desde a formação ao batizado e troca de corda, é um momento em que o capoeirista iniciante tem seu primeiro contato com mestres, contramestres e professores de outros grupos de capoeira ou do mesmo grupo que pertence. Essa cerimônia chamada batizado acontece em um círculo chamado de roda de capoeira, nessa cerimônia o aluno iniciante recebe um nome que chamamos de apelido $^{15}[\ldots . . . "$ (Cruz e Cruz, 2016, p.128)

12 - Há inúmeros relatos de que é um momento propicio para que ocorra o transe na capoeira, momento este que é conhecido como incorporação do "espirito da capoeira", que pode ocorrer com qualquer um que esteja participando da roda, seja, expectador, convidado iniciado, praticante ou capoeirista.

13 - Em evento, "Umbigo da Liberdade: escravidão e africanias no Amazonas", realizado em novembro de 2016 em Manaus, " o mestre Nenel filho de mestre Bimba afirmou ao público presente que não utiliza o sistema de cordas e que a verdadeira capoeira regional é a que foi ensinada e transmitida pelo seu pai. 14 - Em minha passagem de monitor para instrutor, neste caso na condição de formado, fui submetido num jogo com cinco capoeiristas, sendo o propor mestre gigante o último a jogar e posteriormente me nomear para a nova categoria. 15 - Para se ter uma noção sobre os apelidos de grandes Mestres capoeiristas: Pastinha, Bimba, Traíra, Gigante, Curió, João grande, João Pequeno. Há também 
Van Gennep (1997), define determinadas modalidades de ritos, os categoriza como:

\begin{abstract}
Ritos de separação; ritos de agregação e ritos de margem. Os ritos de separação são mais desenvolvidos nas cerimônias de funerais, os ritos de agregação nas de casamento. Quanto aos ritos de margem, podem constituir uma seção importante, por exemplo, na gravidez, no noivado, na iniciação, ou se reduzirem ao mínimo na adoção, na passagem para a segunda ou terceira classe de idade... (Gennep, 1997, p.31)
\end{abstract}

Para Van Gennep (1997), o rito configura-se em fenômeno que apresenta aos agentes a existência de um espaço independente, a possibilidade de manifestação de objeto dotado de uma autonomia relativa, uma fronteira no interior dos grupos humanos. A capoeira pode de acordo com tal proposição teórica ser interpretada como manifestante de "um rito de margem" e "passagem", consequentemente protagoniza mudanças aos indivíduos dentro do grupo, semelhante aos batismos, rituais de iniciação em determinadas religiões, como no catolicismo.

Segundo Van Gennep (1997) os ritos demonstram processos de mudanças, perspectivas de transformação dos indivíduos, em que são fundamentais os processos de iniciação, tais como: batismo religioso, casamento, morte. Criam as alternativas para a aproximação entre dois contextos, ou seja, "Entre o mundo profano e o mundo sagrado há incompatibilidade, a tal ponto que a passagem de um ao outro não pode ser feita sem um estágio intermediário" (p.25).

Em determinadas práticas culturais, como a capoeira, percebe-se um processo gradual de socialização nos ritos de iniciação. O Mestre e os demais integrantes do grupo constroem uma relação de confiança que aumenta

inúmeras referências a nomes de animais, como os mestres: Onça, Gato, Pantera, Canguru, Cobra; Camaleão, etc. 
conforme são superadas as etapas da graduação. Os grupos de adeptos e praticantes se submetem aos rituais de iniciação ou de passagem que possibilitam aos mais jovens o acesso a suas graduações, seja na. Desta forma, praticantes ou iniciados articulam níveis de assimilação de segredos, e comportamentos, seja a partir dos rituais de iniciação, graduação ou responsabilidades que serão assumidas.

Encontramos em Marcel Mauss (2003) em "Técnicas do Corpo", elemento que ele define como "atitude do corpo" assim, modalidades de técnicas de dança e saltos na capoeira, por exemplo, exigem um longo treinamento de técnicas corporais.

Roger Bastide (2001), identifica no universo ritualístico do Candomblé, elementos que tem interferência direta na dinâmica do corpo e comportamento, ou seja, nas cerimonias em que ocorre o fenômeno religioso da possessão, que por sua vez provocara alterações nos gestos dos participantes, sejam, Pais e Filhas de Santo, iniciados ou mesmo expectadores, todos sem exceção podem experimentar uma condição de incorporação de entidades e Deuses.

Bastide categoriza como "Dança dos Deuses" no Candomblé, cuja atuação de Filhas de Santo e convidados, em meio ao salão de dança podem vir a experimentar a condição de Deuses encarnados. Há toda uma alteração nos gestos com as danças e rodopios ao som dos tambores e atabaques, como também "os rostos se metamorfoseiam em máscaras, perdem as rugas do trabalho cotidiano, desaparecidos os estigmas da vida diária, feitas de preocupação e miséria[...]” (p. 39). As cerimonias de capoeira também possibilitam alterações nos gestos e comportamento ao som dos instrumentos característicos. 


\section{Aspectos da Tradição}

A relação dos capoeiristas no que diz respeito à transmissão das tradições, podem ser compreendidas como sobrevivências da herança colonial, mas dentro de um enfrentamento constante que os leva a atuar num processo de reconstrução e construção de sua identidade e comunidade.

Stuart Hall (2003), fala de uma identidade sociológica, que permite ao sujeito preencher o espaço "interior" e "exterior" de um mundo social e público em que "projetamos nossas identidades culturais" num processo em que internalizamos significados e valores, aliados a sentimentos subjetivos em "lugares objetivos. Hall faz referência a um processo que precede o fenômeno das fragmentações das identidades, ou seja, identidades de um sujeito pós-moderno.

Neste sentido, a comunidade de capoeira, é um fenômeno de construção e afirmação de identidade, forjada na luta coletiva, em que os atores, possuem e constroem uma identidade coletiva, precede ao processo de fragmentação das identidades, não esquecendo, segundo, Hall que as “sociedades modernas são por definição sociedades de mudanças...”. No entanto estamos apresentando o confronto entre sociedades que estão no limiar da modernidade no enfrentamento de sociedades tradicionais.

Para Stuart Hall, as identidades se formam em longos processos, não surgem com o nascimento, no caso dos capoeiras, estes no processo de afirmação de sua identidade enfrentaram os diversos mecanismos do poder disciplinar, no qual segundo o autor tem o objetivo de exercer o absoluto controle das atividades diversas do indivíduo, no caso das coletividades mecanismos como : as prisões, manicômios casas de detenção e correção forma instrumentais dos mais utilizados contra os capoeiras, torna-los "dóceis".

\section{Considerações Finais}


A pratica cultural da capoeira em Benjamin Constant, revela inúmeros elementos reflexivos, percebidos pelas experiencias compartilhadas entre aqueles que vivenciam a capoeira e expectadores em suas diversas categorias.

A capoeira possibilita a revelação de universos simbólicos, representações e identidades principalmente dos capoeiristas. Paralelamente há um entrecruzamento de identidades, como: afro-brasileiras, rurais, urbanas, de jovens e crianças.

O batizado pode ser compreendido, como fenômeno anual de caráter místico, histórico-cultural, revelador de identidades e sociabilidades. Ressocializa a capoeira no Amazonas, da vida aos elementos ritualísticos da cultura afro-brasileira em terras tão distantes em seus espaços e lugares de fronteira.

È possível perceber segundo Antônio Arantes (2015), que a praça Frei Ludovico representa um lugar, um espaço comum compartilhado que se define, seja, pelos capoeiristas, vendedores, imigrantes peruanos, fiéis católicos, dentro de um " cotidiano trilhado em que vão sendo construídas coletivamente as fronteiras simbólicas, que separam, aproximam, nivelam, hierarquizam ou numa palavra ordenam as categorias e os grupos sociais" (p.269).

Desta forma se entrecruzam " zonas simbólicas de tradição, onde os sujeitos e o cenário de sua interação...", ou seja, liminares e ambivalentes possibilitando o acionamento das diversas sociabilidades entre os frequentadores e é claro para a capoeira.

$\mathrm{Na}$ praça a capoeira ainda é interpretada como pratica perigosa, marginal, apesar de despertar a curiosidade dos expectadores, na verdade ainda é compreendida dentro do que Perlman (1977) define como "O mito da Marginalidade", ou seja, "...a marginalidade é um mito e também a descrição de uma realidade social. Na qualidade de mito serve de fundamento para crenças pessoais e interesses da sociedade...”. A capoeira dentro desta 
perspectiva ainda vive um processo de interpretação e tradução de seu verdadeiro sentido, em que se entrecruzam suas diversas dimensões: simbólicas, históricas, culturais, de luta, desportiva.

A capoeira transmitida e vivenciada em Benjamin Constant, corresponde ao resultado de ressignificação desta prática cultural, mostra-se muito mais em seu aspecto desportivo, educativo, cabendo aos capoeiristas delimitar os caminhos de uma interpretação dentro do significado de tradição e origens africanas.

\section{REFERENCIAS}

ARANTES, Antônio. A guerra dos lugares: fronteiras simbólicas e liminaridades no espaço urbano de São Paulo. IN: A Guerra dos Lugares. São Paulo: Boitempo, 2015.

BOURDIEU, Pierre. O Poder Simbólico. Rio de Janeiro: Bertrand Brasil, 2008.

CARDOSO DE OLIVEIRA, Roberto. O trabalho do Antropólogo. $2^{\mathrm{a}} \mathrm{ed}$. Brasília: Paralelo 15; São Paulo: Editora Unesp, 2006.

FARIAS, Juliana Barreto et al. Cidades negras: africanos, criolos e espaços urbanos no Brasil escravista do século XIX. São Paulo: Alameda, 2006.

FREIRE, Gilberto. Sobrados e Mucambos: decadência do patriarcado rural e desenvolvimento do urbano. Brasília: Senado Federal, 2004.

GENNEP, A. Van. Os ritos de passagem. Petrópolis: Vozes, 1977.

GEERTZ, Clifford. Obras e vidas: o antropólogo como autor. $2^{\mathrm{a}} \mathrm{ed}$. Rio de Janeiro: Editora UFRJ, 2005.

GOFFMAM, Erving. A representação do eu na vida cotidiana. $20^{\mathrm{a}} \mathrm{ed}$. Rio de Janeiro: Editora Vozes, 2014.

HALL, Stuart. Da diáspora: identidades e mediações culturais. Editora UFMG, 2003.

OLIVEIRA, R.C. A instalação dos índios Terenas no meio urbano. In: Urbanização e Tribalismo. Rio de Janeiro: Zahar, 1968. 
OLIVEIRA, R.C.O. Trabalho do Antropólogo. São Paulo: editora da UNESP, 2006.

PERLMAN, Janice E. O mito da marginalidade: favelas e política no Rio de Janeiro. $2^{\text {a }}$ ed. Rio de Janeiro: Paz e Terra, 1977.

RODRIGUES, G. A. JUSTAMAND, M. CRUZ, T. S. A capoeira em Benjamin Constant: aspectos socioantropologicos.IN: Fazendo Antropologia no Alto Solimões: educação e gênero. São Paulo: Alexa Cultural, 2016.

RODRIGUES, Carmem Izabel. Entre Parentes, vizinhos e amigos Jurunas. In: Vem do Bairro dos Jurunas. Belém: NAEA, 2008.

SOARES, Libano C. R. A capoeira escrava no Rio de Janeiro: 18081850.Tese de doutoramento. Campinas, 1998.

WHYTE, William Foote. Sociedade de esquina [Street Corner Society): A estrutura social de uma área urbana pobre e degradada. Rio de Janeiro: Jorge ZAHAR Editor, 1970. 